\title{
Trenes cordilleranos en documentales argentinos de la década del 40: figuras de integración territorial y trabajo épico ${ }^{1}$
}

\author{
Cordilleran Trains in Argentine Documentaries \\ of the 40s: Figures of Territorial Integration and Epic Work
}

Ximena Andrea Vergara

ximenavergarave@gmail.com

Universidad Central de Chile/Universidad Diego Portales

\section{Resumen}

En este texto se revisa la presencia de imágenes de vehículos motorizados, que aparecen en documentales argentinos de la década del cuarenta, y que dan cuenta de problemáticas como el territorio, la frontera chileno-argentina o el trabajo épico. Se analiza La amistad de dos naciones (Sucesos Argentinos, productor Ángel Díaz, 1942-1943) a partir de tensiones limítrofes entre Chile y Argentina; y El trasandino del Norte (Fernando Ayala, 1949), en relación a la figura del trabajador. Se consideran, como antecedentes o contrastes, filmes del periodo silente argentino y chileno, en este último caso, por medio de registros de prensa.

Palabras clave: Documental institucional argentino, frontera chileno-argentina, trenes, hermandad, trabajo.

\section{Abstract}

In this text we review the presence of images of motor vehicles, that appear in Argentinian documentaries of the 1940s, and that account for issues such as the territory, the ChileanArgentinian border or the epic work. La amistad de dos naciones (Sucesos Argentinos, produced by Ángel Díaz, 1942-1943) is analyzed from boundary issues between Chile and Argentina; and El trasandino del Norte (Fernando Ayala, 1949) is analyzed from the figure of the worker. They are also considered, by way of background or contrasts, films of the Argentinian and Chilean silent period, in the latter case, by means of information that exists in the press.

Keywords: Argentinian institutional documentary, Chilean-Argentinian border, trains, brotherhood, work.

1 Este artículo es resultado del proyecto Fondecyt Regular 1160219 titulado "Imágenes de técnicas en el cine documental latinoamericano: motivos de modernidad y territorio", cuyo Investigador Responsable es Pablo Corro. La autora del texto es coinvestigadora de este proyecto. 


\section{Antecedentes contrapuestos y definiciones}

Las relaciones cinematográficas no ficcionales entre Chile y Argentina se rastrean tempranamente en registros fílmicos de principios del siglo $\mathrm{xx}$, en noticieros de fines de la década del 20 y también en documentales institucionales de las décadas del 40 y 50. Entre los variados motivos, se presentan visitas oficiales, y obras públicas, y en estos pueden rastrearse problemáticas asociadas a la frontera entre ambos países. Se trata de una temática que históricamente ha encontrado un ícono en la cordillera de los Andes, la cual, desde la rama de la geografía social, ha sido cuestionada en tanto figuración de un límite. En este caso, el historiador Andrés Nuñez ("La frontera") ha tensionado la usual comprensión de la montaña como "barrera, línea o raya cuya omnipresencia natural sirve para separar dos naciones, la chilena y la argentina” (90), apuntando al lugar opaco en que quedarían múltiples procesos socioculturales:

De esta suerte, el dominio discursivo de la cordillera como sinónimo de frontera o límite colaboró a que ella, la cordillera, la montaña, perdiese otras lecturas, otros saberes, como por ejemplo los asociados a una cordillera social y cultural. Es decir, la cordillera física se impuso, en la escala nacional, a la cordillera cultural. En otras palabras, la cordillera de Los Andes fue jerarquizada como frontera política y natural entre dos países, ocultando o encubriendo saberes locales o referencias específicas que hacían de ella un espacio de sociabilidad más que de barrera o muralla (90).

Para comprender este discurso, Núñez menciona con respaldo interdisciplinar ${ }^{2}$ que la equivalencia entre la frontera política y cordillera se habría constituido como idea fuerte muy avanzado el siglo xIx, e incluso a inicios del xx, en paralelo a los procesos de la construcción de los Estados-nación. Como parte de este proceso, la idea de una línea, de una frontera cordillerana, generó productos culturales variados. Pero también, la noción de integración cordillerana fue presentándose en ambientes de tensiones limítrofes entre Argentina y Chile, lo cual puede rastrearse en registros cinematográficos que se encargaron de documentar e informar al espectador de episodios de fin de conflicto, comúnmente concretados y celebrados por medio de visitas mutuas. Efectivamente, un tópico destacado dentro del cine temprano y que permanece en el documental institucional es el de las visitas oficiales, un ritual de poder, al que podemos agregarle el adjetivo de trasnacional, en tanto se esfuerza en

2 La línea de estudio desarrollada por Núñez desde la geografía social se enmarca en un enfoque desarrollado también desde distintas disciplinas: "Unos fundan su análisis desde la lógica de las articulaciones económicas, otros desde el ámbito etnohistoriográfico y otros desde una visión antropológica, por nombrar algunas perspectivas de análisis" ("La frontera” 100). Ver también "De la montaña geográfica a las geografías de montaña. Un análisis de Los Andes chileno desde la geografía social" (Núñez, Arenas y Sánchez). 
estrechar las relaciones de las élites políticas de distintos países. ${ }^{3}$ Particularmente, y a modo de ejemplo decidor, dentro de la cinematografía chilena temprana, los años 1902 y 1903 fueron llamativamente productivos, y entre los filmes de los que existe constancia en la prensa, destacan un amplio conjunto de vistas o actualidades vinculadas a la celebración del Tratado de Equivalencia Naval, Paz y Amistad, más conocido como Pactos de Mayo. ${ }^{4}$ Los pactos fueron firmados en mayo de 1902 y celebrados en septiembre de ese año en Santiago y venían a aliviar tensiones limítrofes y armamentistas (Lacoste, "Chile y Argentina”). Dentro de las variadas cintas exhibidas, destaca El paso de la cordillera del excelentísimo señor Terry en su viaje a Buenos Aires de The Automatic Biograph, casa productora de los españoles Juan José Pont y Pijoan Trias. En el filme, se registraba el viaje de regreso del ministro plenipotenciario José Antonio Terry a Argentina, y si bien se encuentra perdido, cuenta con una nota de prensa excepionalmente larga para la época, que detalla el trayecto:

La partida a Buenos Aires del Ministro arjentino señor Terry y comitiva. Llegada del señor Ministro y comitiva a la estación del ferrocarril trasandino en los Andes, para tomar el tren y seguir viaje al Salto del Soldado. Llegada del tren al Salto del Soldado. La máquina saliendo del túnel del Salto y llegada a la estación. Descenso de los pasajeros: el señor Ministro Terry. Don Napoleón Peró, don M. Sarratea Pinto y don Armando Peró y demás pasajeros. Salida de los coches de la empresa Transportes Unidos del Salto del Soldado con los pasajeros para seguir viaje al Juncal. Llegada a Guardia Vieja, desfile de las mulas de los Transportes Unidos que van a tomar los pasajeros para pasar la cumbre. Partida de los coches de la

3 El concepto "ritual de poder" ha sido fundamental en el estudio del cine silente tanto brasilero como chileno, y permite pensar también otras cinematografías del continente. En la década del 70, en su estudio sobre el caso brasilero, Salles propuso los términos "cuna espléndida" y el de "ritual de poder". El primero hacía referencia al culto a las bellezas naturales de Brasil, y el segundo, apelaba a los registros vinculados a actos políticos, en gran medida asociados al presidente de la República. De acuerdo con Villarroel, este último concepto fue ampliado por Bernardet, para quien "El ritual del poder no está determinado por el hecho que se filma, no es el asunto o el tema el que determina el ritual, sino el tipo de producción o el enfoque con el que se aborda un determinado tema" (53). Asimismo, en la colección Resgate do Cinema Silencioso Brasileiro (2008), y considerando que luego del estudio de Salles se descubrieron y restauraron muchísimos filmes nuevos, Souza señala que "Ritual do Poder matiza-se também en diferentes rituais da elite - política, econômica, eclesiástica, militar, etc." (5). A lo largo de su libro Poder, nación y exclusión en el cine temprano. Chile-Brasil (1896-1933), Villarroel dialoga, problematiza y amplía las posibilidades de los ritos de poder, luego de un análisis comparativo entre filmes sobrevivientes chilenos y brasileros.

4 Efectivamente, luego del vacío cinematográfico que caracterizó el periodo que va entre los años 1898 y 1901 —en 1897 el pionero Luis Oddó daba inicio a la historia del cine chileno con la filmación de 5 vistas, de 1900 solo se tiene registro en la prensa de Las carreras de Viña del Mar, y de 1901 no existe, a la fecha, constancia de ningún registro documental-, en 1902 se retoma la actividad fílmica. Dentro del conjunto de materiales de 1902 y como forma de dar seguimiento al hito histórico que fueron los Pactos de Mayo, se filmaron y fueron estrenándose paulatinamente, en octubre, filmes como Desfile de veteranos del 79 frente a delegación argentina o El San Martín en aguas chilenas de la empresa The Automatic Biograph, propiedad de los españoles Juan José Pont y Pijoan Trias. En 1903 continuaron los estrenos, destacando filmes de la casa productora Biógrafo Universal de la Empresa Centenera y Ca. como La llegada del San Martín, Gran matiné a bordo del San Martín, Banquete a los argentinos en el cerro Santa Lucía o Torneo a florete en el San Martín. Asimismo, esta última casa productora estrenó en Chile filmes sobre la también especial y oficial visita que realizó una delegación chilena a las fiestas patrias argentinas en mayo de 1903, destacando Llegada de la escuadra chilena a la rada y entrada a la dársena de Buenos Aires y Encuentro de las escuadras chilena y argentina en alta mar y saludos de ordenanzas. Véase más información en Matiz ("Los Pactos de Mayo (1902): Filmar la familia militar en el vecindario"). 
Guardia Vieja y primera repechada que suben. Ascenso de la cordillera por el lado chileno. Las mulas trepando a la cumbre. El Ministro señor Terry acompañado por su guía. La Galvany, el barítono Paccini, el maestro Zucchi y varios artistas de la compañía de ópera y demás pasajeros. La bajada de la cumbre por Bermejo (lado arjentino). Los pasajeros descienden a mulas. Llegada a la posada de las Cuevas. Las mulas descansando. Los pasajeros parten del Paramillo de las Cuevas en los coches de los Transportes Unidos para seguir al Puente del Inca. Ferrocarril en marcha" (El Mercurio, Santiago, 19 de noviembre de 1902, 5).

Esta filmación del trayecto, que dialoga con la cinta Ferrocarril trasandino que uno de los pioneros del cine argentino, Eugenio Py, registró también en el marco de la firma de los Pactos de Mayo, ${ }^{5}$ otorga un desglose detallado del cruce cordillerano por medio de la alusión explícita a partidas, llegadas, descensos y ascensos. Se trata, de acuerdo al interés que tenemos aquí por materiales fílmicos existentes, de un gesto que volverá a replicarse a inicios de la década del 40. Pero antes, en otro momento prolífico del cine chileno, como fue el Centenario de 1910, volvieron a exhibirse filmes de partidas y regresos. En este caso, una comisión argentina liderada por el presidente José Figueroa Alcorta venía a celebrar las fiestas chilenas, y de este paso resultaron cintas como Llegada del Colegio Militar argentino a la Estación Central, Llegada a Santiago del Excmo. señor Figueroa Alcorta y comitiva o Regreso del Excmo. señor Figueroa Alcorta a Buenos Aires, todas de la productiva Compañía Cinematográfica del Pacífico. En estos casos lo central es el espacio protagónico de la estación de tren, destino final luego del cruce de la cordillera de los Andes por medio del icónico Ferrocarril Trasandino, que unía la ciudad argentina de Mendoza con la chilena Los Andes, y que permitió fomentar las relaciones políticas entre ambos países:

Los gobiernos de ambos países se aprestaron aprovechar esta oportunidad con viajes de gran valor simbólico: la disponibilidad de un viaje rápido y seguro a través de la cordillera permitió organizar el primer viaje de un Presidente chileno a Buenos Aires y el de un Presidente argentino a Santiago. Se planificaron ambas cumbres presidenciales para el 25 de mayo y el 18 de setiembre de 1910, para coincidir con las solemnes celebraciones del Centenario. El lanzamiento de las cumbres presidenciales fue interpretado por la prensa de la época como un símbolo de la nueva etapa que se abría en las relaciones bilaterales (Lacoste, "Vinos, carnes, ferrocarriles" 104).

5 Juan José Pont y Pijoan Trias no fueron los únicos en registrar trayectos trasandinos vinculados a la firma de los pactos de 1902. Eugenio Py, francés radicado en Argentina, había viajado a Chile al momento de la firma junto al periodista Enrique Casellas, y con espíritu aventurero "se ubican en el frente de la locomotora, donde atan el trípode al paragolpes delantero y a una barra transversal" (Barrios Barón 45) y corren numerosos riesgos durante la marcha del tren. De esta aventura surge el filme Ferrocarril Trasandino; del paso a Chile a lomo de mula surge En los Andes; y ya en Chile Py filma aproximadamente 20 cintas. Ver Catálogo LePage n. ${ }^{\circ}$ 130, junio de 1904. 
En este caso, es relevante mencionar también que el tren que posibilita los tránsitos políticos forma parte de un entramado retórico mayor. Efectivamente, el cine de no ficción de la época temprana, por medio de la insistente presencia de imágenes de medios de transporte y de hitos urbanos, se constituía como medio de figuración de lo moderno y reproducía las grandes victorias de la técnica: sobre el espacio vertical (edificaciones, ascensores, aeroplanos); y sobre el espacio horizontal (dominio de las grandes distancias por medio de los transportes modernos). En relación con esto último, es posible señalar que la altura de la cordillera, además de establecerse como límite que se vence de acuerdo al impulso horizontal de conquistar el territorio, da cuenta del sometimiento técnico de la altura.

De esta forma, en el cine de no ficción temprano se presenta otra forma de cruce cordillerano, que se contrapone al paso vinculado a las estructuras de poder: la cordillera se constituye también como un espacio atravesado por máquinas de trabajo. Con relación a esto, Pablo Corro ha analizado un "muestrario diacrónico" (que le permite unir materiales de la época silente con documentales del siglo xxI) en que se presentan, entre otros, vehículos motorizados como grúas, aplanadoras, bulldozer, trenes, camiones mineros, y que dan cuenta de que "las relaciones entre hombres y máquinas en el cine documental, considera las variaciones poéticas de lo nuevo, de lo moderno, del principio de racionalización de lo orgánico y lo inorgánico, del sometimiento o padecimiento de las energías, como otra fenomenología, también consecutiva, la del movimiento circundante en el siglo precedente" (s. p.). En el caso del cine de no ficción silente, Corro ha analizado el emblemático documental institucional Mineral El Teniente (1919) del italiano Salvador Giambastiani, encargado por la Braden Cooper Co., propietaria del yacimiento mineral de Sewell. En su análisis, Corro ha destacado los trenes que "desplazan las materias extractivas pero más notoriamente representan la eficiente y veloz conectividad del hito productivo cordillerano con la Capital" (s. p.); ha detectado cierto "sabotaje al guion institucional" que se ve en el aparecer de niños; y algo que es de particular interés para este trabajo es la atención que ha puesto en la ausencia de una masa trabajadora y la idea de que los distintos vehículos motorizados que trasladan al obrero dan cuenta del tópico de la conectividad elevada que ofrece la modernidad técnica de la Braden Cooper.

Habiendo revisado ya dos polos vinculados al cruce cordillerano que se presentaron en la época silente chilena, y que fueron detectados en notas de prensa, en filmes sobrevivientes o en revisiones críticas, lo que sigue es la observación de la rearticulación de estas tensiones en filmes argentinos institucionales de la década del 40. Para esto, es de utilidad primero delimitar ciertas características de este tipo de producciones y que se encuentran hermanadas con los llamados noticieros cinematográficos, formato de la no-ficción que logró sistematizar y reunir las filmaciones llamadas "actualidades", breves filmes de contenido noticioso característicos del 
primer cine. ${ }^{6}$ Focalizándose en el caso argentino, Luchetti entrega una minuciosa sistematización de la discusión bibliográfica sobre los noticiarios, incluyendo un desvío hacia los documentales institucionales por haber compartido usos y formas con las entregas cinematográficas informativas. Es por esto que la particularidad del documental institucional funciona desde la diferencia, y así lo deja claro Luchetti, al mismo tiempo que cuestiona el estigma investigativo de estos materiales: ${ }^{7}$

En primer lugar, tales documentales eran en su mayoría producidos por las empresas encargadas de la realización de los noticiarios. En segundo lugar, ambos forman parte de un mismo modo de producción y distribución industrial: carácter seriado y anónimo, formato estándar, alcance masivo. En lo relativo al contenido y a las formas expresivas, en tercer término, la única gran diferencia radica en que el noticiario está formado por un conjunto misceláneo en tanto el documental se limita a un único tema. Por último, ambas producciones se sirven del material de archivo - tanto imágenes en movimiento de ficción y de no-ficción, como imágenes fijas, provenientes de otros medios y soportes (fotografías, grabados, pinturas) - y utilizan como recurso las dramatizaciones o escenificaciones. En ellas se emplean, por otra parte, recursos típicos del cine costumbrista argentino (321).

En el marco de esta misma discusión sobre definiciones operativas, Franco y Marrone mencionan la mayor complejidad fílmica de los documentales, la evidencia de un discurso elaborado y, sobre todo, la presencia de una doble marca autoral. Por un lado, los documentales pertenecerían a un autor institucional (el gobierno que prescribe el guion), y por otro, a quien realiza el filme, ya sea explícitamente con nombre propio, o implícitamente, dado que era común que los filmes no fueran firmados, y solo atribuidos a las casas productoras, como Sucesos Argentinos, en este caso. En lo que sigue, se realiza una búsqueda de estas voces y tonos que permiten problematizar figuras técnicas, recursos fílmicos, y discursos institucionales.

6 Para el estudio de los noticieros ver Baechlin y Muller-Strauss; McKernan; Tranche y Sánchez Biosca; y Tosantos. Para el caso chileno ver Vergara y Krebs ("Prolongaciones de la prensa" y "Recurrencias temáticas").

7 Entre los estudios que aluden al documental institucional argentino destacan "El noticiario cinematográfico y el documental: géneros patrióticos" (Allegretti, Marrone y Moyano Walker); "El noticiario cinematográfico como género" (Allegretti); “ "El noticiario cinematográfico y el documental institucional en la segunda posguerra. Un caso: la representación de las políticas sociales en España y Argentina" (Franco y Marrone). Estos tres textos pertenecen a un libro fundamental en el estudio de estas temáticas, Persiguiendo imágenes. El noticiario argentino, la memoria y la historia (1930-1969), editado por Irene Marrone y Mercedes Moyano Walker. En cuanto a la puesta en valor del estudio de este tipo de materiales, Luchetti retoma discusiones previas y señala "De este modo, salvo contadas excepciones, el noticiario cinematográfico y los documentales clásicos o institucionales han sido excluidos de las discusiones más importantes de este campo de estudios, considerándolos, a lo sumo, antecedentes remotos del documental. Las variables tomadas en consideración para rechazar la pertenencia de estas producciones al campo de la producción documental versan sobre sus faltas o carencias (falta de calidad artística y de experimentación, de independencia, de un punto de vista — debido a la pretensión de neutralidad) o remiten a consideraciones de índole ideológica (promoción de un discurso y de actitudes comunicacionales de pasivas en el espectador)" (303). 


\section{Cruzar la cordillera}

Vimos previamente cómo en dos de los años más abundantes de la producción fílmica chilena temprana (1902 y 1910) se presentaron episodios de integración que fueron retratados por medio del cine, con el refuerzo de imágenes de ferrocarriles o elementos vinculados, como las estaciones. Se trata de un enlace que volverá a aparecer en la década del cuarenta, desde el lado argentino y cuando las relaciones entre documental, poder y Estado esbozadas tempranamente, ya están institucionalizadas. En este marco es donde se sitúa La amistad de dos naciones (1942-1943), filme de 10 minutos realizado por Sucesos Argentinos, producido por Ángel Díaz, encargado por la Subsecretaría de Informaciones y Prensa y, por tanto, alineado al discurso oficial. ${ }^{8}$

En el documental en cuestión se registra la visita de una comisión liderada por el ministro de Relaciones Exteriores argentino Enrique Ruiz Guiñazú a la transmisión de mando en la que Juan Antonio Ríos asumiría la presidencia de Chile, luego de la inesperada muerte de Pedro Aguirre Cerda a fines de 1941. Aquí, tal como en los filmes vinculados a los Pactos de Mayo de 1902, se presenta el tópico de la visita oficial en el marco de una tensión territorial, en este caso producida durante la Segunda Guerra Mundial. Estados Unidos había pedido fortificar el estrecho de Magallanes con elementos navales que permitirían vigilar y proteger esta zona altamente estratégica, y si bien en un comienzo Chile se niega, luego del ataque de Pearl Harbor acuerdan con Argentina revisar un tratado de 1881 que prohibía levantar fortificaciones en el estrecho (Nocera). Firman un acuerdo pero finalmente Argentina se retracta y vuelven a tensionarse las relaciones para luego acabar alivianándose nuevamente.

8 En el artículo "Una lectura de Sucesos Argentinos", Clara Kriger señala que con una "prematura intuición multimediática”, el empresario Ángel Díaz creaba en 1938 el noticiario sonoro Sucesos Argentinos, que duraría hasta 1972 y que de forma paralela al noticiario produjo documentales. Definiendo sus rasgos y buscando continuidades y discontinuidades en los patrones formales de este noticiario que cruzó el peronismo, uno de los temas que aborda Kriger es la relación entre Sucesos Argentinos y el Estado. De acuerdo a la autora, al inicio Sucesos Argentinos se financiaba con la recaudación de las exhibiciones en sala y con publicidad encubierta, lo cual no habría sido suficiente y derivó en que durante los años 40 Sucesos contaría con subsidios estatales en el marco de medidas que planteaban como obligatoria la exhibición de noticiarios en todas las funciones y salas. A partir de esto, Kriger señala que "Estas medidas convierten a Díaz en un empresario totalmente dependiente del Estado, más precisamente del beneplácito de la Subsecretaría de Información y Prensa", aunque aclara que "De todas maneras Sucesos, y los estudios cinematográficos en general, no funcionaban como empresas estatales (o compradas por testaferros que respondían al gobierno peronista) como sucedía con gran parte de la prensa gráfica y radial" (8). En este punto es relevante mencionar que la Subsecretaría de Informaciones y Prensa, creada en octubre de 1943 durante la dictadura del general Pedro Pablo Ramírez, fue una entidad que dependía de la Secretaría de la Presidencia de la Nación y que, de acuerdo a Arribá estaba conformada por ocho áreas, una de las cuales era la Dirección General de Espectáculos Públicos (Cine y Teatro). Más particularmente, Luchetti y Ramírez Llorens acotan que bajo la jurisdicción de esta Dirección se crea la Dirección de Cinematografía, la cual tenía como funciones: "a) intervenir en el examen de la calidad moral y cultural de los espectáculos públicos, b) estimular la producción de noticiarios cinematográficos y películas documentales de interés nacional, $c$ ) el fomento de la cinematografía y del teatro nacional, y d) intervenir en el abastecimiento de película virgen" (74). Cabe señalar que el hecho histórico que documenta La amistad de dos naciones (1942-1943), la visita del ministro argentino Enrique Ruiz Guiñazú a la transmisión de mando de Juan Antonio Ríos, ocurrió en abril de 1942, es decir, previo a la creación de la Subsecretaría de Información y Prensa. Sin embargo, dado que la película finaliza con el logo de la entidad, se deduce que fue estrenada con posterioridad al suceso histórico. 
Unos meses después de este altercado es cuando viene Guiñazú, y en el documental se presentan un discurso en off vinculado a la unión política que se persigue, y que verá nuevamente en la cordillera un motivo de integración. Por un lado, se detecta un relato oficial dictado por la institucionalidad, y por otro lado, se presentan estrategias fílmicas que funcionan como correlato estético de este discurso. El filme se inicia con la imagen del Monumento al Ejército de Los Andes, dedicado al general San Martín, construido por el escultor uruguayo Juan Manuel Ferrari, inaugurado en 1914, y ubicado en la cima del Cerro de la Gloria, mirador de la ciudad de Mendoza. La voz en off rememora el episodio de liberación liderado por el prócer argentino y señala que: "Fue en el año 1817 que el gran capitán organizara su ejército para trasponer Los Andes llevando aires de libertad a los pueblos hermanos sojuzgados”. Seguido de esto, y en un gesto de actualización de la historia, se señala que: "En 1942 Argentina renueva sus expresiones de inalterable amistad hacia el pueblo hermano". Lo que sigue, y con el tono de una crónica de viaje, es la narración del cruce de la cordillera. Con remembranzas a la ruta arcaica de los próceres, y tal como sucedía en El paso de la cordillera del excelentísimo señor Terry en su viaje a Buenos Aires de 1902, se va detallando el cruce de la cordillera:

En autos debe cubrirse el trayecto que separa Mendoza de Punta Vacas, lugar de partida del Ferrocarril Trasandino. El doctor Ruiz Guiñazú y su comitiva hacen un alto en Cruz de Panamillo a más de tres mil metros sobre el nivel del mar. Llegamos al valle de Uspallata que da su nombre al paso por donde el General Las Heras condujera a parte del ejército de San Martín hacia la nación hermana. Continuando nuestro viaje entre maravillosas [...] arribamos al histórico puente de Picheuta, por aquí cruzaron las huestes libertadoras hace más de 23 lustros. Punta Vacas, enviados especiales del gobierno chileno adelantan su saludo a la misión argentina, integrada en parte por el canciller Ruiz Guiñazú [nombres...], acompaña a nuestra delegación el Embajador de Chile, Doctor Ríos Gallardo. Parte el tren para ganar la fragosa ruta. Perspectiva imponente de los altos picachos andinos.

Si por un lado la voz off explicita las relaciones históricas y detalla los lugares, desde el lado de las imágenes se presentan los vehículos de unificación: los autos desde Mendoza a Punta Vaca y el Ferrocarril Trasandino que traslada a la comisión a Chile. Con el acompañamiento de un inclusivo "nosotros", que hace partícipe del viaje al locutor y que proyecta un sentido patriótico al espectador potencial, en el recorrido filmado los vehículos motorizados rememoran el cruce a pie y a caballo de los próceres, y con imágenes de medios de transporte modernos, el trayecto es puesto en escena. Con esto, y de acuerdo a hipótesis de una frontera como lugar de integración, tenemos que la exposición del trayecto funciona como correlato de la anulación de las fronteras y refuerza el discurso de hermandad, aunque es posible detectar también ambivalencias. Con relación a esto, es fundamental la escena en que enviados especiales del Gobierno 
chileno "adelantan" — como dice la voz en off — el saludo a la delegación argentina en la estación de Punta Vacas. Primero, y del lado de la ambivalencia, la frontera se muestra militarizada, y resguardada. Pero, en segundo lugar, y poniéndose en escena la idea de integración, se muestra la partida del tren trasandino, como dice el locutor: "Parte el tren para ganar la fragosa ruta". Lo que sigue es una toma en phantom ride, clásico recurso del cine temprano, posible técnicamente por la instalación de la cámara en la parte delantera de tren (u otros medios de transporte) y que otorga una sensación fantasmal, como la ensayada tempranamente en Panorama Pris d'un Train En Marche dirigido en 1898 por George Meliès. Aquí, el phantom ride acompañado de un musicalizado y algo infantilizado sonido de tren provee un plano general de la cordillera, que funciona como reforzamiento de la monumentalidad de una montaña que puede ser atravesada. Pasando por lagunas, admirando la cumbre del Aconcagua o recorriendo un puente ferroviario, la cámara montada en el tren proyecta un episodio simbólico de superación de una frontera tanto geográfica como política, que alivia la tensión de la fortificación del estrecho de Magallanes.

Más delante, ya arribada la comisión a Santiago, la cámara, de acuerdo a un tono turístico adulador, recorre la capital, una opulenta ciudad, como dice el locutor. Se retratan, entre otros, el soberbio rascacielos en que se alojan comitivas extranjeras, el monumental Barrio Cívico, lugares emblemáticos como el Parque Forestal o el cerro San Cristóbal. Más tarde se narran las actividades clásicas de una visita oficial y para el tema que aquí nos interesa, es decidora una frase con sonido directo pronunciada en el marco de los discursos emitidos por el embajador Guiñazú y el embajador chileno Ríos Gallardo. Efectivamente, luego de que la cámara muestra la imagen de un monumento a San Martín, que remite al inicio del filme, Ríos Gallardo expresa que Guiñazú "pronuncia un elocuente discurso, reafirmación de la tradicional amistad que une a los pueblos argentino y chileno, fortalecida a través del tiempo por anhelos fraternos y comunes desde el día en que O’Higgins y San Martín sellaron con un abrazo los vínculos inquebrantables de las dos grandes naciones de Sudamérica”. Como se desprende de estas palabras del embajador, y también de la línea narrativa del filme, el discurso de la amistad de las dos naciones, al mismo tiempo que se sostiene en la idea de una integración territorial por vía cordillerana, recurre a viejos símbolos de amistad como lo es el abrazo, que también será reutilizado por Perón. ${ }^{9}$

9 En su estudio sobre los rituales políticos escenificados por Perón en un conjunto de visitas de Estado que fueron filmadas, Insarrualde señala que en el caso del abrazo operaría una apropiación de símbolos preexistentes, que serían resignificados. Como dice este autor en su análisis del documental Dos pueblos unidos (1953), que trata sobre la visita de Perón a Chile cuando Carlos Ibáñez cumplía su segundo mandato como presidente (1952-1958), la alusión a O’Higgins y San Martín funcionaría como un gesto de "legitimación simbólica crucial" ya que "demuestra que la relación de hermandad chileno-argentina se ve refrendada por una tradición emancipadora histórica, encarnada en los próceres de los dos países y en su actuales presidentes" (134). Sin poder hacer aquí un análisis de Dos pueblos unidos, dado que forman parte de un complejo discurso de hermandad hilvanado en los gobiernos de Perón e Ibáñez, destacamos brevemente el inicio y cierre del filme, dada su sintonía con La amistad de dos naciones. Este documental, de casi 30 minutos de duración, sigue al detalle las actividades realizadas por Perón en Santiago y abre con un intertítulo que une banderas y cordillera, seguido por una imagen pictórica del abrazo. En este inicio, 


\section{Excavar la cordillera}

Considerando La amistad de dos naciones como evidencia de un discurso de época que recurre a la imagen del tren a partir de una potencia unificadora que estrecha lazos de poder, es posible revisar ahora otro material fílmico de la década del 40 que también se sitúa en la frontera, aunque diversificando el sentido: la cordillera es recorrida, excavada y atravesada por máquinas de trabajo. Se trata de El trasandino del Norte, documental de 9 minutos dirigido por Fernando Ayala y producido por Emelco, empresa que marca un episodio fundamental en el vínculo cinematográfico entre Chile y Argentina. El filme trata sobre la construcción de la línea férrea que unió a Salta con el puerto chileno de Antofagasta, un proyecto que tuvo una historia de seis décadas, y al que se le conoce con nombres diversos como Huaytiquina, Trasandino del Norte o, actualmente, como el turístico Tren de las Nubes. Fue inaugurado en los primeros años del gobierno de Perón (1946-1955), y de acuerdo a información promocional de la época, "Perón realiza un sueño de Yrigoyen: el ferrocarril Salta-Antofagasta" (Folleto Ferrocarril Salta-Antofagasta, 20 de febrero de 1948, cit. en Benedetti). Asimismo, de acuerdo a Benedetti, a lo largo del proceso de construcción se fueron creando tres imágenes: el ferrocarril como "objeto de fascinación", como "puerta al progreso" y como "medio civilizador", que lograría sacar de su aislamiento al Territorio de Los Andes (17). Se trata además, de una obra ferroviaria asociada claramente a la épica, y este es justamente el tono que atraviesa el cortometraje.

Observando el material, es relevante señalar primero que a pesar de que el nombre de Perón no es explicitado en el filme, sí se presentan marcas de una cinematografía institucional que de acuerdo al libro Cine y peronismo. El estado en escena de Clara Kriger, tuvo sus años "prodigios" entre 1949 y 1952, viendo también en la ficción y en la docuficción un medio de transmisión ideológica. En estos momentos, y tal como venía gestándose con la creación de la Subsecretaría de Informaciones y Prensa antes referida, hubo un aumento en la protección a la industria cinematográfica por parte del Estado, al mismo tiempo que existió una marcada preocupación a nivel de contenido: "Las películas no debían lesionar los sentimientos patrióticos de la comunidad argentina, sus símbolos y el acervo histórico de la nacionalidad [...]" (52). Más específicamente, en el caso del documental, se detectan dos tipos de piezas: las que darían cuenta de las obras "realizadas por instituciones estatales o paraestatales como resultado de las políticas de estado del periodo" (113), tales como el agro, la

\footnotetext{
la voz en off hace referencia a la superación de los obstáculos territoriales al señalar: "Y hoy en otra etapa decisiva de la vida de los pueblos americanos, nuevamente Chile y Argentina superan los obstáculos naturales de la enorme cordillera para unirse estrechamente como amigos, o más aun, como hermanos". Como respaldo visual de la idea, la cordillera se presenta desde una vista aérea y ahora desde el aire reproduce el mismo propósito de enlazamiento geográfico simbólico de La amistad de dos naciones. Hacia el final, y reforzándose esta idea, se relata el regreso de Perón a Buenos Aires y se acentúa que "el tren está llegando a nuestra patria marchando por caminos de esa cordillera convertida en eslabón de nuestra fraternal unión".
} 
vivienda, o las obras públicas, y luego estarían los filmes centrados en el peronismo: en actos públicos, en adhesiones populares, y otros, focalizados en los líderes Domingo y Eva Perón.

Considerando lo anterior, lo primero es decir que El trasandino del Norte da cuenta de una obra pública, y como forma de recalcar su relevancia, se menciona lo que existía previo a la obra. De esta manera, el filme se inicia con imágenes de la región altiplánica de Puna, empobrecida y aislada, como dice el locutor, por una "valla imponente de la montaña majestuosa, desafiante" que se condice con un plano general de una montaña no intervenida y seca. Al cierre del filme, Puna es ya una zona con desarrollo económico gracias a la vía férrea, y lo que relata el documental es justamente la osadía de los hombres que hicieron posible la construcción del tren luego de, como dice el locutor, "sortear las vallas de la cordillera". Aparece aquí la figura del trabajador, una "masa-pueblo feliz", ${ }^{10}$ "los titanes", como se les llama, y se va destacando una épica del trabajo que se sostiene en planos generales de obreros cavando, o de trabajadores alejándose y corriendo de las explosiones dinamiteras con ecos de una película western. En contrapunto, se presentan elementos visuales que personalizan a la masa trabajadora: primeros planos de palas, martilleos de obreros particulares y la colocación manual de los rieles. En este sentido, el tren, este ícono técnico y estético ampliamente presentado en la cinematografía documental latinoamericana más temprana (en las llegadas en tren de personajes ilustres o en los trenes revolucionarios del cine mexicano), se presenta aquí en proceso de construcción. Asimismo, hay una apropiación del tren por parte del trabajador, y esta idea es clara cuando los obreros son trasladados por el tren montados sobre él, poblándolo y desbordándolo. Y se ve, finalmente, un uso del phantom ride que otorga audiovisualmente un sentido de progreso, reforzado por una direccionalidad enérgica, que al mismo tiempo que visibiliza una ruta en construcción, resalta el protagonismo de los trabajadores en esta dinámica de avance. Se trata, asimismo, de un gesto que recalca la armonía entre el trabajador y el Estado, y que se desliga de problemáticas como la salubridad, la explotación y, sobre todo, el trabajo infantil que se presenta en el documental. Asimismo, y reproduciendo el discurso de $\mathrm{La}$ amistad de dos naciones, el tren se constituye también como emblema de hermandad entre Chile y Argentina, como dice la voz en off: "Fue fiesta grande para el norte [...] Cientos de trenes atravesarán la Puna, marcha acelerada rumbo al puerto de

10 En su estudio sobre la representación de las masas en el cine argentino, Marrone detecta cómo esta figura se moldearía de acuerdo a periodos políticos, conformándose como "procesión cívica y manifestación de correligionarios" en los actos yrigoyenistas; como "pueblo feliz" en la época de Perón; y como una "ciudadanía republicana" en gobiernos tanto democráticos como dictatoriales. Por su parte, en otro de sus estudios, Kriger ("Los trabajadores") analiza la presencia del trabajador en periodos del cine argentino a partir de la conformación de planos. Para la época que interesa aquí, señala que en el peronismo habría habido un cambio en la estrategia, y la reunión en un mismo plano de multitudes y líderes políticos daría cuenta del ascenso político de las masas. Asimismo, la autora destaca el protagonismo de los uniformes en tanto "armonía homogeneizadora", y entre variados ejemplos menciona uniformes de enfermeras, trajes de baños infantiles o los clásicos overoles del trabajador. 
la nación hermana. Y cada uno de ellos será el motor propulsor de nuevas industrias, de nuevas esperanzas. La tarea de transportar esa inmensa riqueza que aflora sobre la tierra, será una tarea grata y el esfuerzo de los hombres, fructificará en el progreso de la nación".

\section{Un contraste}

Hasta acá, hemos visto cómo imágenes de trenes han funcionado operativamente en pos de una unificación territorial entre Chile y Argentina, tensionada y destensionada en diferentes momentos del siglo xx; y también, como objeto de construcción épica y de progreso. Respondiendo a una doble marca autoral - por un lado, la voz de la institucionalidad, y por otro, la voz de un realizador que propone estrategias fílmicas, de acuerdo a Marrone-, La amistad de dos naciones y El trasandino del Norte presentan usos originales de esta imagen técnica, dando cuenta de cómo en el estéticamente cuestionado documental institucional se reformulan figuras reiteradas del documental latinoamericano. Como contraste y cierre, volvamos a retroceder a la época temprana, en este caso, al filme sobreviviente Por tierras argentinas (1926), producido por Valle Film y que tiene una duración de más de 40 minutos. En esta película lo que se busca es dar cuenta de los límites de Argentina, de sus localidades y de su fuerza de trabajo. Como documental centrípeto, que mira el territorio-nación a partir de una idea de la cordillera como borde, reproduciendo la idea dominante de acuerdo a Núñez, la película se nutre del uso canónico del tren. Efectivamente, el tren unifica el territorio propio, acercando a las provincias y, como dice el intertítulo, activa "la circulación de las riquezas y acercando entre sí las poblaciones, el riel hizo de la Argentina el país donde toda iniciativa prospera rápidamente”. Los trenes aquí revisados pretenden, en cambio, deshilvanar un borde montañoso.

\section{Referencias}

Allegretti, Susana, Irene Marrone y Mercedes Moyano Walker. "El noticiario cinematográfico y el documental: géneros patrióticos”. Persiguiendo imágenes. El noticiario argentino, la memoria y la historia (1930-1960). Comps. Irene Marrone y Mercedes Moyano. Buenos Aires, Editores del Puerto, 2006, pp. 3-16.

Allegretti, Susana. "El noticiario cinematográfico como género". Persiguiendo imágenes. El noticiario argentino, la memoria y la historia (1930-1960). Comps. Irene Marrone y Mercedes Moyano. Buenos Aires: Editores del Puerto, 2006, pp. 17-30. Arribá, Sergio. "El peronismo y la Política de Radiodifusión (1946-1955). Mucho ruido, pocas leyes: economía y políticas de comunicación en la Argentina (1920-2004). Ed. Guillermo Mastrini. Buenos Aires, La Crujía, 2005, pp. 71-100. 
Baechlin, Peter y Maurice Muller-Strauss. Newsreels across the World. París, UnEsco, 1952.

Barrios Barón, Carlos. Pioneros del cine en la Argentina. Cardini, Py y Ducros Hicken. Buenos Aires, edición del autor, 1995.

Benedetti, Alejandro. "El ferrocarril Huaytiquina, entre el progreso y el fracaso. Aproximaciones desde la geografía histórica del territorio de Los Andes". Revista Escuela de Historia, Facultad de Humanidades Universidad Nacional de Salta, año 4, vol. 1, n. ${ }^{\circ}$ 4, 2005.

Corro, Pablo. Breve historia del trabajo mecanizado en el documental chileno. Inédito. Dos pueblos unidos. Secretaria de Prensa y Difusión de la Nación, 1953.

El trasandino del Norte. Dirigida por Fernando Ayala, 1949.

Franco, Marcela e Irene Marrone. "El noticiario cinematográfico y el documental institucional en la segunda posguerra. Un caso: la representación de las políticas sociales en España y Argentina”. Persiguiendo imágenes. El noticiario argentino, la memoria y la historia (1930-1960). Comps. Irene Marrone y Mercedes Moyano. Buenos Aires, Editores del Puerto, 2006.

Insarrualde, Gustavo. "Exportando imaginarios. Rituales políticos en las visitas de estado del presidente Perón vistos desde la óptica de los noticiarios cinematográficos (1952-1954)". Cuadernos de Historia. Serie Economía y Sociedad, n. ${ }^{\circ}$ 17, 2006. Kriger, Clara. "Una lectura de Sucesos Argentinos" (2007). Acta académica XI Jornadas Interescuelas/Departamentos de Historia. Departamento de Historia. Facultad de Filosofía y Letras. Universidad de Tucumán, San Miguel de Tucumán, 2007.

-_. Cine y peronismo. El estado en escena. Buenos Aires: Siglo xxi, 2009.

- - "Los trabajadores, entre el uniforme y la fiesta". Masas, pueblo, multitud en cine y televisión. Coords. Mariano Mestman y Mirta Varela. Eudeba, Buenos Aires, 2013, pp. 89-103.

La amistad de dos naciones. Producido por Ángel Díaz, Sucesos Argentinos, 1942-1943. Lacoste, Pablo. "Chile y Argentina al borde de la guerra (1881-1902)". Anuario del Centro de Estudios Históricos Prof. Carlos S.A Segreti, vol .1, n. ${ }^{\circ} 11,2001$.

- - "Vinos, carnes, ferrocarriles y el Tratado de Libre Comercio entre Argentina y Chile (1905-1910). Revista Historia, n. ${ }^{\circ} 37,2004$, pp. 97-127.

Luchetti, Florencia y Fernando Ramírez Llorens. "Filmar la realidad. Cine y Estado: la consolidación del documental como vehículo de propaganda (1926-1944)". Persiguiendo imágenes. El noticiario argentino, la memoria y la historia (19301960). Comps. Irene Marrone y Mercedes Moyano. Buenos Aires, Editores del Puerto, 2006.

Luchetti, Florencia. "El noticiario argentino en Argentina. Un estado de la cuestión". Aniki, vol. 3, n. ${ }^{\circ}$ 2, 2016.

Marrone, Irene. "La excepción y la regla. El cine informativo entre el acto político y la protesta social”. Masas, pueblo, multitud en cine y televisión. Coords. Mariano Mestman y Mirta Varela. Eudeba, Buenos Aires, 2013. 
Matiz, Camilo. "Los Pactos de Mayo (1902): Filmar la familia militar en el vecindario". Vivomatografías. Revista de estudios sobre precine y cine silente en Latinoamérica, n. ${ }^{\circ}$ 6, 2020, pp. 317-347.

McKernan, Luke, ed. Yesterday's News: The British Cinema Newsreel Reader. Londres, British Universities Film \& Media Council, 2002.

Mineral El Teniente. Dirigido por Salvador Giambastiani, 1919.

Nocera, Raffaele. Chile y la guerra, 1933-1943. Santiago, Centro de Investigaciones Diego Barros Arana, Lom, 2006.

Núñez, Andrés, Federico Arenas y Rafael Sánchez. “De la montaña geográfica a las geografías de montaña. Un análisis de Los Andes chileno desde la geografía social". Journal of Alpine Research/Revue de géographie alpine, n. o 105-4, 2017.

Núñez, Andrés. "La frontera no deja ver la montaña: invisibilización de la cordillera de Los Andes en la Norpatagonia chileno-argentina”. Revista de Geografía Norte Grande, n. ${ }^{\circ}$ 55, 2013, pp. 89-108.

Por tierras argentinas. Valle Film, 1926.

Souza, Carlos Roberto de. "Resgate do cinema silencioso". Librillo DVD Resgate do cinema silencioso Brasileiro. São Paulo, Cinemateca Brasileira, 2008

Tosantos, Carlos María. Cine y periodismo. Los complementos. Barcelona, Ediciones del Serbal, 2004.

Tranche, Rafael y Vicente Sánchez Biosca. NO DO. El tiempo y la memoria. Madrid, Cátedra, Filmoteca Española, 2006.

Vergara, Ximena y Antonia Krebs. "Prolongaciones de la prensa moderna. Difusión masiva e inmediatez en los noticieros cinematográficos chilenos (1927-1931)”. Memorias y representaciones en el cine chileno y latinoamericano, Coord. Mónica Villarroel. Santiago, LOM, 2016.

——. "Recurrencias temáticas en los noticieros cinematográficos chilenos (1927-1931): deportes e idearios de gobierno". De Ruiz a la utopía contemporánea en el cine chileno y latinoamericano. Coord. Mónica Villarroel. Santiago, LOM, 2017.

Villarroel, Mónica. Poder, nación y exclusión en el cine temprano. Chile-Brasil (18961933). Santiago, LOM, 2017.

Enviado: 10 de abril de 2019

Aceptado: 23 de enero de 2020 